\title{
MARRIAGE AND DIVORCE COUNSELLING STRATEGIES IN BORNO STATE, NIGERIA
}

\author{
IBRAHIM T. BOKKO, $L P C N, C C N$
}

\begin{abstract}
This paper discussed marriage and divorce counselling strategies. The objective of which is to demonstrate how counselling can maintain marital stability and avoid, minimize and manage divorce and post-divorce crisis among couples. Marriage is a 'give and take' relationship whichshould be 'till-deathdo us apart' affair. Some basic principles of marriage are approval of the couples, payment of bride prize and religious rites, and possible problemsof divorce among couples include psychological, social and economic, and causes of divorce are poverty, promiscuity, poor feeding and infertilityto mention but a few have been enumerated.Family Ecological Equilibrium Interaction, Family Cognitive Restructuring, Family Psychosocial Harmony Restoration and Group Crisis Intervention strategies were proposed as counselling strategies to increase family stability and mitigate divorce among couples.
\end{abstract}

\section{Introduction}

Mustapha, Mburza and Goni, (2010), defined marriage as a union borne out of love between two persons which affirms a love that confirms social recognition and a gateway to legal procreation, responsibility, and beliefs. Osiki, (1995), explained that, marriage is the agreement between two individuals to become husband and wife in a healthy relationship. The couples must have understood themselves as people who are coming from different family backgrounds that will live on'give and take' relationship. Marital contract should be seen as 'till - death do -us - apart' relationship where every partner contributes to the success of long relationship. Osiki, (1995) conducted a survey research on marital duration, age and childlessness as they affect marriage stability among couples in Ibadan. The study revealed that, age of marriage, duration and family size affect the quality of a marriage. She maintained that marriage contracted at less than 21 years in males and 19 years in females tend to end in divorce. Nwobi, (1997), opined that, marriage has been described as legalizing relationship between man and woman which the community approves. The use of 'between man and woman' in the definitions of marriage no longer stand the test of time. It is worth noting this time around in $21^{\text {st }}$ century that unisex marriage is been promoted in almost all the western world, 'man marrying a man as husband and wife and woman marrying a woman as husband and wife'. This practice has cometo stamp out traditional man/woman marriage and the idea of procreation since none of the two groups can bear to give birth to a child. Marriage puts both parties and society under certain rules (legal and obligations). It is the contract and obligation that makes the two to be called husband and wife. This relationship sometimes can be either positive or negative depending on thepsychological wellbeing of the couples.

Nwobi, (1997), maintained that, marriage is one of the social acts initiated by early people of the race. It has established principles of contracting which depends on cultures of the couples where the marriage is being contracted. However, there are some principles that are unique. These include; approval of both parties, payment of bride prize, and religious rites. It is this legal obligation that gave the legality of procreation and rise of family. 
Anyama and Nwongigwe, (2010), observed that, there is a significant relationship between marital adjustment and marital stability. Marital relationship emphasizes the notion or practice of reciprocity (give and take) to translate carrying as interpersonal relationship. It is very important that your needs and the needs of your partner are met in a helpful way, (Prior, 2013). Ideally, the relationship supposed to be life-long or until death. Nwobi, (1997), assert that, those partners that expect much from their spouse see marriage as positive and strive to perfect it, while those that see marriage as a problem find it difficult to perfect it. Kolo, (2010), observed that, marriage is the ultimate beginning of family life. He adds that, when marriage is marked with genuine love, sense of understanding, and respect between couples, positive perception and trust for one another will result in family stability. Conversely, when marriage is contracted on false, suspicious, and negative perception of the roles of partners it will lead to family instability. He observed that, there are some traits that foster understanding, love and trust that support family stability among couples. Family pre-destination, recognition of diverse personality traits, sustained tolerance, making the family the source of inspiration, consultation and decision making, respect for family values, institutionalization of support for family members irrespective of circumstances and spiritual (religious beliefs), (Kolo, 2010).

Divorce has been defined by Nwobi, (1997), as a means of terminating a legal contract of marriage. It is used as a legitimate technique of dealing with unhappy marriage. However, she observed that, divorce causes problems among the couples. These include; loss of sexual partner for sexual satisfaction, economic and social adjustment, shelter and care of children. She opined that, break - up of a marriage has a serious ripple effect on the relationship with a wider circle of friends, relatives and in-laws. Osiki, (1995), conducted a survey research on marital duration, age and childlessness as they affect marriage stability among couples in Ibadan relates that, there is high rate of divorce recorded among young couples due to various physical and psychological problems. Nwobi, (1997), observed that,among other psychological problems the couples might experience include; lack of sexual commitment by one of the couples, infertility, and failure to obey prescribed modes of behaviours. However, as noted earlier, the practice of unisex will now remove infertility as a cause of divorce among couples.Mustapha,Mburza and Goni, (2010), in a research conducted on causes of divorce among couples in Maiduguri Metropolis revealed that, poverty, promiscuity, poor feeding; squander mania of food items and impotency or infertility as major causes of divorce. Nwobi, (1997), highlighted some factors that distract marriage which include, peer groups, in-laws, inter-faith marriage, incompatibility, step-mother/child syndrome, illness, communication breakdown, childlessness, role enactment and over possessiveness. Marriage and Family, (2013), observed that symptoms of marital problems include; verbal-abuse, in-law interference, lack of sexual intimacy, out of control spending, infertility, poor communication, addiction and parenting disagreement. It also highlighted on some marital problems which include; impatience, jealousy, selfishness, lack of forgiveness, mistrust, anger, fear and deep emotional wounds. Cnn.com/health, (2009), maintained that, among other prominent causes of divorce are; Infidelity, Divorce, Substance abuse, Physical or mental conditions, Same-sex relationship issues, Cultural clashes, Finances, Unemploymeit, Blended families, Communication problems, Sexual difficulties, Conflicts about child rearing, Infertility, Anger and Changing roles, such as retirement. 


\section{Counselling Strategies for Family Stability}

Marriage counselling aims at enhancing interpersonal relationship ofcouples to maintaining marriage agreement satisfactorily. Marital counseling helps to couples understand and reduce conflicts and improve their relationship, (cnn.com/health, 2009). It gives the couples tools to communicate better, negotiate differences in a healthy way. Counselling should bean interactive process through which the family is assisted to regain homeostatic balance for members to be comfortable. The counselling intervention can either be pre-marital or post-marital. The counsellor can use Directive, non-Directive and Eclectic approaches of counselling through which the counsellor can extend confidentiality, acceptance, understanding, genuineness, empathy, and unconditional positive regard to the client. The counseling should be provided by a professionally trained and licensed 'marriage and family therapist' with a specific focus on couples relationship.Among other strategies to be used include;

\section{Family Ecological Equilibrium Interaction}

This counselling skill is to stabilize such burst of activities that might directly or indirectly affect the family stability. Family ecological equilibrium studies those things that go around in family both among the couples, children and the immediate or extended family members that live together that might distract the family relationship. For instances, some members of the family are too lazy or do not give helping hand in the management of affairs in the family. This interaction will give the whole family opportunity to discuss their problems amicably in form of group counselling.Group counselling in a family is to create equilibrium intervention either structured or unstructured interventions, (Kolo,2010), this is to stabilize psychological and social dysfunctions among the couples to make the family resolve or cope with the challenges.

\section{Family Cognitive Restructuring}

Uwe, (2006), maintained that, Rational-Emotive Therapy emphasizes thought process and emotions as crucial in determining human behavior. Man according to Rational-Emotive is uniquely rational, as well as irrational, that when man is thinking and behaving rationally will be effective, happy and competent but when a man behaves irrational and illogical thinking he will be biased and prejudice in thinking. Since couples are from different family and or socio-cultural backgrounds, the dynamics of thought process (regional, cultural, racial) and emotions of the couples will determine their attitudes and behavoiurs as a result affects their family stability, (Kolo, 2010). Nigeria today, in fact Borno State in particular, is witnessing inter and intra- cultural and as well as religious marriage. Couples from different cultural and religious background are coming to accept each other and get married. The two could manage to live, but the extended relations that did not comprehend importance of inter-marriage will demand much from their in-law as just they demand from their son or daughter. This therefore will create tension in the other party that is not of same culture or religion of the other members of the family. The strategy will focus on creating relationships, arousing interest in the family stabilityand sensitizing family members on faulty perceptions that goes among them by changing their thinking strategies towards respect to family issues. Family cognitive restructuring is to engender stability and mitigate instability in the family. 


\section{Family Psycho-social Harmony Restoration}

This is a counselling strategy that looks at the awakening relationship in couples. It is to awake the adjustment needs toward changing family slightdifferences of social changes, (Kolo, 2010).PRPH, (2013), maintained that, Psycho-social Harmony is to offer family members skill building opportunities that are rehabilitative in nature. The use of sociodrama will be very effective in this condition of counselling. Community outings and activities will also be of significant importance.

\section{Group Crisis Intervention}

This counselling technique is in line with Reality Therapy Model. It is six steps approach through which the couples will eliminate irrational thinking about their marriage. Nwobi, (1997) observed that, there is the need to involve children in the group process. The steps are;

(i) problem definition (ii) confidentiality (iii) support both verbal and nonverbal, (iv) examining other possible alternatives (v) tentative actions solutions (vi) clients to take positive actions.

The counsellor is to evaluate severity of the crisis, appraise the clients thinking, feelings, and behaviours; determine the length of the counselling, look for the contributing factors, (Henderson and Thompson, 2011). The counsellor can use Eclectic approach in counselling and considers other problems for referral, and alternative coping procedures.Wubbolding, 2007 as cited in Henderson and Thompson, (2011), suggested WDEP system in group process in counselling. W stands for (wants), D stands for (direction and doing) $\mathrm{E}$ stands for (evaluating what the client wants) and $\mathrm{P}$ stands for (plans of action for change). This model will increase the family communication and participatory in understanding the family problems. Reality Therapy states that people have to assume responsibility for the outcome of their behaviours. They have to choose to change before new behavior can be effective.

\section{Challenges of Marital Counselling in Nigeria}

Marital Counselling has numerous challenges in Nigeria. Among other problems are; Inadequate trained marriage and family therapist. Nigeria has in adequate trained marriage counsellors that could handle marriage and divorce cases in society. Considering the African culture of early marriage across the gender, couple with challenges of adolescence, social and economic factors, divorce rate is high among the couples in Nigeria. The existing counsellors are not conversant with the available counselling strategies that could be used to handle and manage family crises.

Lack of public counselling centers. There are no public counselling centers in Nigerian society. The available counsellors are school based counsellors who serve in institutions of learning. There are more or less trained to help school students with minordevelopmental and academic cases. Therefore, their services are limited to school environment where the lager society do not benefit.

Non availability of multi-religious counselling theories. Most of the existing theories are foreign and cannot fit to tackle marital cases in other religions because of their 
peculiarities. The three popular religions in Nigeria are Islamic Religion, Christian Religion and Traditional Religion, each of these religions has one thing that does not match to the other. Therefore, need separate and peculiar counselling treatment.

\section{Ćonclusion}

Marriage is a social factor that extends ripple relationshipamong the families of the two couples and communities. It is a means of legalizing relationship among man and woman which the community approves therefore, need to be respected and cherished. Counsellors and psychotherapists should try to maintain the homeostatic balance of marriage among the couples by extension of family education and counselling intervention for creation of equilibrium and family stability. There is the need to introduce pre-marital counselling for couples tounderstand themselves before marriage is contracted.

\section{Recommendations}

1. There is the need to identify some effective counseling skills and strategies that will best promote marital stability among couples in Nigeria.

2. There is the need to develop indigenous marital theory that will arrest cultural, ethnic and inter-religious counselling in Nigeria.

3. Compulsory pre-marital counselling among intending couples should be in forced in Nigeria. 


\section{Réference}

Anayama, S.C. \&Nwadinige, I.P. (2010).Marital Adjustment for Counselling. Lagos Counsellor: 3 (1): 62-69.

Cnn.com/health, (2009).Marriage Counselling: Working through Relationship Problems. Cable News Network. A Time Warner Company. All Rights Reserved Retrieved 5/6/2013. From: http://edition.com/HEALTH/livingwell/boomer.health

Henderson, D. A. \& Thompson, C. L. (2011). Counselling Children: International Edition (8thed.). USA: BROOK/COLE CENGAGE Learning.

Kolo, I. A. (2010). Key Strategies for Family Stability Counselling. The Counsellor, Ibadan, 27 1-6 Esthom Graphic Prints

Marriage and Family, (2013), Marriage and Family Christian counselling. Retrieved on 15/7/2013. From: http://www.livinglifecounselling.com

Mustapha, U, Mburza, A. \& Goni, U. (2010). Causes of Divorce among Couples in Maiduguri Metropolis, Borno State, Implication for Counselling. The counsellor, Ibadan. Bright Way Pub. 28: 21-28

Nwobi, P.C. (1997). Marriage and Family Counselling: Enugu, Nigeria. PAN-AFRIC Publishers.

Osiki, J. O. (1995). Marital Duration, Age and Childlessness as they affect marriage Happiness. Nigerian Journal of Clinical and Counselling Psychology, Ibadan, I (1): $34-42$

PRPH, (2013). Psychosocial Rehabilitation Program Harmony. Lapeer Count Community Mental Health. Retrieved: 23rd January, 2013. From: www.lapeerchm.org/program

Prior, E. (2013). Long-Term Relationship Problems with 24 of most common issues. www.professional-counselling.comRetrieved 8/6/2013

Uwe, E. A. (2006). Theories of Counselling and Psychotherapy. Calabar, Nigeria. ElSaphire Ltd. 